\title{
The social fabric of understanding: equilibrium, authority, and epistemic empathy
}

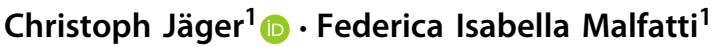

Received: 23 June 2019 / Accepted: 30 June 2020 / Published online: 14 July 2020

(c) The Author(s) 2020

\begin{abstract}
We discuss the social-epistemic aspects of Catherine Elgin's theory of reflective equilibrium and understanding and argue that it yields an argument for the view that a crucial social-epistemic function of epistemic authorities is to foster understanding in their communities. We explore the competences that enable epistemic authorities to fulfil this role and argue that among them is an epistemic virtue we call "epistemic empathy".
\end{abstract}

Keywords Epistemic authority · Authority · Reflective equilibrium · Understanding · Epistemic empathy $\cdot$ Holism · Catherine Elgin

\section{Introduction}

One of the most vibrant developments in current epistemology is the exploration of epistemic ends and values other than knowledge, most notably understanding. However, exactly what understanding consists in and what it requires, are still highly controversial. An original approach is Catherine Elgin's proposal that so-called objectual understanding (specifically, of a given topic or domain) is a matter of creating or improving reflective equilibrium in one's system of thought (Elgin 1996, p. 118, 2017 , pp. 3-4). On Elgin's holistic account, such a system consists not only of particular factual judgments or beliefs, but also of theoretical commitments, acceptances, ${ }^{1}$ generalizations, methods of inquiry, standards of justification, and epistemic goals and values (Elgin 1996, p. 106, 2017, p. 102). Call such a system a noetic network. In what follows, we discuss Elgin's equilibrium analysis of understanding and argue that, among other merits, it has the potential to provide a seminal perspective on the social-epistemic function of epistemic authority: appropriately reconstructed, the

\footnotetext{
1 In her use of this term, Elgin roughly follows Cohen (1992).

$凶$ Christoph Jäger

christoph.jaeger@uibk.ac.at

1 University of Innsbruck, Innsbruck, Austria
} 
account highlights the way in which epistemic authorities can foster understanding in their epistemic communities. This conclusion departs significantly from current mainstream approaches to epistemic authority, which locate its key function in the social transmission of true beliefs or knowledge. Our argument is this.

Many if not most of an agent's attempts to straighten out noetic dissonance have an essentially social dimension. As Elgin herself notes, when we try to achieve reflective equilibrium we often profit from the division of cognitive labor (see, e.g., Elgin 1996, p. 118,2017 , pp. 4, 59, 108, 112). Of course, we do not always need to consult others, ${ }^{2}$ but when complex theories come under pressure from new data, for instance, or when customary standards, methods, or principles of reasoning appear to lose their reliability, cognitive reformation rarely proceeds as a solipsistic enterprise. When noetic disruptions like these befall us, we are often at a loss to decide on our own which elements of our networks to abandon or adjust (and how to do this rationally), and which ones to preserve. What should we do in such cases?

What typically comes to the rescue is engagement with epistemic authorities. Epistemic authority, as we construe the notion, is a relation between an epistemic agent (or group of agents) S, a given topic or subject matter A, and some other epistemic agent (or group of agents) $S^{*}$ who enjoys a sufficient degree of epistemic superiority over $\mathrm{S}$ with respect to $\mathrm{A}$. This may involve $\mathrm{S}^{*}$ 's possessing more evidence or more (first-order) factual information than S. However, epistemic authorities are also more conscientious or reliable (or both) in handling the evidence: they possess superior methodological skills and more advanced higher-level competences to pursue certain sorts of epistemic aim. An agent may be an epistemic authority for you vis-à-vis topic A but not topic $\mathrm{A}^{*}$, and she may be an epistemic authority regarding A for me, but not for you. Moreover, $\mathrm{S}$ may catch up with, or even outperform, $\mathrm{S}^{*}$ at some point, be it because $S^{*}$ loses competence or information or because $S$ gains it over time. This suggests that epistemic authority should also be relativized to times: $\mathrm{S}^{*}$ is an authority for S, regarding A, at or during a given (period of) time t. Note that this characterization focuses on an "objective" sense of the notion. Individuals and communities may (and, alas, often do) regard certain people as epistemic authorities who actually fail to possess the competences that would qualify them for this role. Such agents serve as mere de facto or mere reputational authorities, but fail to constitute "real" authorities. ${ }^{3}$

The fact that we often (rationally) turn to epistemic authorities in order to create or reinstate reflective equilibrium in our noetic networks has the following interesting consequence. Suppose we agree with Elgin that creating reflective equilibrium produces or deepens understanding. Then epistemic authorities often serve as sources of understanding for their interlocutors. This conclusion differs significantly from tradi-

\footnotetext{
${ }^{2}$ An example from Elgin: "My tenable belief that trash is collected on Tuesdays needs no support from the experts. My own experience bears it out. Still..., without the resources the community provides, I could neither formulate nor justify the belief in question" (1996, p. 116).

3 Our characterization covers both domain-relative authority and what we may call general testimonial authority. If you ask a random passerby what time it is, you will usually trust her reply and accept her as an authority on the matter. It is controversial whether such assertions or tellings, just by constituting tellings, generate conversational or perhaps even moral pressure to accept them as authoritative. [For discussions see, e.g., Hinchman 2005, 2014; Moran 2005; Fricker 2007; Greco 2016; and the detailed exploration in Goldberg (manuscript)]. We will not discuss this issue here, focusing instead on domain-relative authority. Nevertheless, much of what we say will also apply to general testimonial authority.
} 
tional approaches. For example, in her influential book Epistemic Authority: A Theory of Trust, Authority, and Autonomy in Belief (2012), Linda Zagzebski says that she is "interested in the special case in which I have reason to believe that another person is more likely to get the truth about some question than I would be if I attempted to get the answer to the question by a direct use of my faculties" (2012, p. 105). "In cases of these kinds", she continues,

the conscientious thing to do is to let the other person stand in for me in my attempt to get the truth in that domain and to adopt his belief. This in broad outline is what I mean by epistemic authority (Zagzebski 2012, p. 105).

Zagzebski's approach is inspired by Joseph Raz's theory of political authority and his application of it to "theoretical authority". Raz argues that:

[j] ust as with any practical authority, the point of theoretical authority is to enable me to conform to reason, this time reason for belief, better than I would otherwise be able to do ( $\operatorname{Raz} 2009$, p. 155; see also 1986, p. 68).

Similarly, arguing that "practical authority tells you what to do", Edna UllmannMargalit maintains that "[t]heoretical authority tells you what to believe" (UllmannMargalit 2007, pp. 54, 57). The examples could be multiplied. ${ }^{4}$ The epistemic goal that these and many other authors consider is not understanding, but the (rational, conscientiously guided) acquisition and transmission of true belief. Yet, many have argued in recent years that understanding is not reducible to acquiring or sustaining true beliefs or even to knowledge. ${ }^{5}$ If such anti-reductionism about understanding is correct, then belief-transmission models of epistemic authority cannot account for the fact that epistemic authorities often produce understanding in their interlocutors. In any case, even if one accepts reductionism, our argument shows that epistemic authority is good for far more than transmitting individual beliefs: it can also promote the richer and more ambitious epistemic goal of improving complex noetic networks in terms of understanding.

A related issue is the role of testimony in general. Various authors have explicitly argued that, whereas testimony can be a distinctive source of true beliefs and knowledge, it cannot be a source of understanding (see, e.g., Zagzebski 2008, pp. 145-146; Hills 2009; Pritchard 2010, p. 81). If our argument is on target, we must demur. Epistemic authorities of the sort in question can, by entering into testimonial relations, produce understanding in their interlocutors. Or so we shall argue. ${ }^{6}$ One interesting consequence is that, if understanding is an achievement (as many argue), then, in the

\footnotetext{
4 Others who discuss epistemic authority in terms of belief-transmission include Friedman (1990) and McMyler (2011).

5 An opposing view, however, is defended by Chris Kelp (see, e.g., Kelp 2017). Sliwa (2015) also argues for a reductionist view of understanding, though she focuses on knowing-why. For a helpful discussion see Ross (2018), who presents a counterexample to the view that understanding reduces to knowledge, but is sympathetic to the more general reductionist idea that understanding is reducible to other types of epistemic state.

6 Our argument thus follows up on Jäger's thesis (2016), that what he calls "Socratic authorities" can be a source of understanding. It also concurs with Boyd (2017), who argues that testimony in general can yield understanding. Boyd approaches the question indirectly, however, by looking into (real and alleged) asymmetries between knowledge and understanding. He then argues that none of these asymmetries can
} 
cases of epistemic improvement discussed here, significant credit for this achievement goes not just to the agent, but to the epistemic or intellectual authorities he or she consults. We conclude, therefore, that there are processes we can aptly call "understanding transmission" and that such processes involve a distinctive distribution of epistemic responsibility.

Before developing this argument in detail, some clarifications and disclaimers are in order. First, we said that Elgin is concerned with so-called objectual understanding of a given topic or domain. Examples include understanding climate change, understanding US politics, understanding libertarian theories of free will, and so forth. This kind of understanding is commonly distinguished, for example, from factual understanding of a single event or phenomenon (e.g., the election of Donald Trump); propositional understanding (that this mushroom is toxic); explanatory understanding (why the house burnt down); practical understanding (how to operate a chain saw); or symbolic or semiotic understanding (what a text, a diagram, a work of art means). That said, it should be noted that — as Elgin would agree - these distinctions turn out on closer inspection to be fuzzier than they may at first appear. For example, understanding a single event is not a piecemeal matter. It involves understanding why the event occurred as well as how its explanation is systematically connected with other aspects of the domain. Similarly, understanding a phenomenon such as current global warming requires symbolic understanding of theories about climate change and thus of the propositional and non-propositional representations they involve. ${ }^{7}$

Second, we will not make heavy weather of the claim that epistemic agents strive for balance in their noetic networks. Granted, some people seem better able to tolerate, and less apt to suffer from, noetic distortions and incoherencies than others. What matters most for present purposes is the normative claim that agents should aspire to reinstate cognitive balance when things have gotten out of whack - that there is rational pressure to do so. Note that this does not in itself presuppose ambitious holistic interpretations. For example, even epistemological foundationalists (of knowledge or justification, for example) agree that agents ought to organize their minds systematically and that there is rational pressure to straighten out cognitive dissonance. Here we will not venture to defend this assumption but will simply accept it.

Third, note that we deliberately talk about "producing or deepening/approaching understanding". Understanding is gradable. Reflective equilibrium should thus turn out to be gradable too. This makes sense; after all, balance need not be perfect. The tightrope walker may struggle but still keep her balance-even though she would be better off, safer, more stable, if her pole were not tilted. From a holistic point of view, a noetic network approaches equilibrium when epistemically relevant relations such as support relations in some (ideally non-isolated) subsystem, or connections between different subsystems, are multiplied or strengthened. This is typically not an all-or-nothing affair, but a matter of approximation.

In the next section, we clarify the notion of reflective equilibrium and identify ways in which agents may encounter trouble in their noetic networks. Section 3 explains

Footnote 6 continued

account for the alleged fact that understanding cannot be acquired via testimony. For recent arguments in this vein, see also Grimm (2020).

7 For some initial reflections on this topic see, e.g., Malfatti (2019). 
why epistemic agents must often consult epistemic authorities to preserve, achieve, or approach reflective equilibrium; Sect. 4 distinguishes experts from authorities. Section 5 looks at the competences or epistemic virtues that such authorities need to fulfil this role. Recent discussions of epistemic authority have largely focused on laypersons or novices, ${ }^{8}$ asking how they should rationally react to the views of epistemic authorities. ${ }^{9}$ But what about authorities themselves? Which skills and virtues will they possess and exercise when they promote understanding in their epistemic communities? We argue that an important intellectual virtue in this context is what we call epistemic empathy.

\section{Approaching reflective equilibrium}

The notion of reflective equilibrium figures in two ways in the literature. On the one hand, it denotes a state of cognitive balance; on the other, it refers to the procedures or cognitive dynamics that yield such states (see e.g. Kelly and McGrath 2010; Walden 2013; Brun 2014; Cath 2016; de Maagt 2017; Baumberger and Brun 2016). Although the term was originally introduced in logic and ethics (Goodman 1953; Rawls 1971), ${ }^{10}$ in recent literature reflective equilibrium is portrayed broadly as a "procedure for investigating ... [a given] domain" (Kelly and McGrath 2010), "a deliberative process in which we reflect on and revise our beliefs about an area of inquiry, moral or nonmoral" (Daniels 2016, p. 1). Some see it as nothing less than the "the status quo" of all philosophical reasoning (Ellis and McBrayer 2019) or even "the ... rational method of inquiry" in general (DePaul 2005).

Where do such processes start, and how do they proceed? According to Elgin, we have no choice but to commence in medias res, i.e., begin with those "opinions, values, methods, and standards that we consider relevant and ... that we have some inclination to accept" (Elgin 2017, p. 64). Such contents enjoy "initial tenability" (Elgin 1996, p. 102). She also reminds us that "our convictions form the basis for our actions" and that "confidence in a given judgment indicates that we have not yet found it an impediment to action" (ibid.). ${ }^{11}$ The best way to interpret Elgin here, we suggest, is as

\footnotetext{
8 A layperson is in an epistemically inferior position with respect to experts or authorities, but need not be a complete ignoramus in the relevant domain. Novices are beginners who have little if any knowledge about the subject matter, but aspire to reach an advanced level in the discipline. That said, we shall often use "layperson" and "novice" interchangeably.

9 See, e.g., Keren (2007, 2014), Zagzebski (2012, 2014, 2016), Anderson (2014), McMyler (2014), Benton (2014), Jäger (2016), Wright (2016), Dormandy (2018a), Croce (2018a, b, 2019), Constantin and Grundmann (2018) and Stewart (2019).

10 John Rawls coined the term "reflective equilibrium" to characterize a state of coherence between particular moral judgments and general moral principles (Rawls 1971, pp. 46-53). The general idea goes back to Nelson Goodman, who argues that particular inferences, both deductive and inductive, are justified if they proceed in "agreement" with general principles and that, vice versa, the principles are justified if they match our actual inferential practice (Goodman 1953, p. 64).

11 Rawls's cure was to sanction only the subset of "considered" judgments and to discard those that are formed with hesitation or under emotional pressure (Rawls 1971, p. 47).
} 
saying that we have an initial reason to accept a certain content, as long as accepting it does not frustrate our success in action. ${ }^{12}$

The problem, however, is that people are often inclined to accept cognitive products of bias, idiosyncrasy, delusion, or other manifestations of irrationality. (And indeed, unfortunately we not only do this initially.) For example, "superstitions, delusions, and prejudices begin their careers as initially tenable beliefs" (Elgin 1996, p. 102). So how should the method proceed from what appears "initially tenable"? Elgin says that "[c]onsistency is mandatory", (1996, p. 103). But this requirement is not as easy to fulfill as it might appear. Not every contradiction is explicit, and some, whether explicit or implicit, are harder to detect than others. Moreover, it is often unclear how contradictions, once identified, should be resolved. This will typically not be a matter of simply rejecting certain contents and accepting others. Instead, we might have to restrict, or redraw, the conflicting claims' scope or domain of application. And consistency does not suffice for equilibrium anyway: beliefs or acceptances might be consistent yet mutually irrelevant. For a system to be in reflective equilibrium, its elements must also "hang together", be "mutually supportive", and be "reasonable in light of one another" (Elgin 1996, p. 99, 2017, pp. 72, 98). Moreover, none of this ensures, or even makes it probable, that the network correctly represents the phenomena it deals with. Still, lifting it into equilibrium is "the best we can do in the epistemic circumstances" (Elgin 2017, p. 64).

Suppose, then, that you do your best to apply the method properly. You adjust your initially tenable beliefs and commitments (via appropriate revisions and expansions of the network) until all requirements of reflective equilibrium, as far as you can tell, are fulfilled, at which point you cease your noetic rearrangement. The resulting network may nonetheless fail to achieve equilibrium. For things could easily go wrong in the "reflective" part of the method: our meta-level assessments may go awry. "Appearances can be deceiving. We may believe, with reason, that a system is in equilibrium when in fact it is not" (Elgin 1996, p. 14).

In order to see where epistemic intervention from others can help, it will be useful to distinguish the various ways in which a noetic system may fail to be in reflective equilibrium. Two basic considerations are whether or not the system is in balance and whether or not the agent is reflectively aware of this. As far as we can tell, theorists of reflective equilibrium have not offered in-depth analyses of the "reflective" part of the notion. Daniels (2016), in the passage quoted above, characterizes the procedure as a "deliberative process in which we reflect on and revise our beliefs about an area of inquiry". However, the objects of such deliberation are not exhausted by beliefs. Recall that in Elgin's approach, the targets also consist of acceptances, commitments, methods, standards, epistemic goals, and so forth. Moreover, deliberation itself may be construed as a cognitive process that yields beliefs, states of acceptance, commitments, and the like. It also yields higher-order knowledge, in which case we shall say that the agent "is aware" of the system's condition. For simplicity's sake, let us look at such cases and cases in which agents lack such awareness.

\footnotetext{
12 Note that this might be one reason why Elgin claims that, although "coherence plays a major role" in her account of reflective equilibrium, her theory should not be read as a pure coherence theory (Elgin 2017, p. 63). See also Ebertz (1993), McMahan (2000), Pust (2000) and Cath (2016) for criticisms of strict coherentist interpretations of the method of reflective equilibrium.
} 
First, consider an imbalanced system. The agent may become aware of some or all of the imbalances - call this a state of reflective imbalance. She may nevertheless have no idea how to reform the network. Secondly, she may also fail to become aware of the imbalances, for example because she never engages in any in-depth assessment of her noetic network in the first place (call this unreflective imbalance). Third, often people not only lack awareness of the poor status of their systems, but even positively believe that the latter are in balance when they are not. In such cases, agents suffer from illusions of balance. Next, consider a system that is in balance. Once more, the agent may be aware of this, a state we may call reflective balance (so far the only epistemically good case); or she may be unaware of the balance (unreflective balance), or even falsely believe that the system is imbalanced (illusion of imbalance).

More distinctions could be drawn. We have noted already that noetic balance is not an all-or-nothing affair. Moreover, the reflective part too is gradable. Sometimes our self-assessments produce outright beliefs, but we also harbor partial or graded beliefs about the (degrees of) balance that our noetic profiles enjoy. However, we shall set aside further complications here; what matters is that the method of reflective equilibrium aims at delivering epistemic results that are, as Elgin puts it (2017, pp. 67, 11), reasonable in the overall "epistemic circumstances" and not just relative to the best of an agent's subjective ability to assess her cognitive network. What, then, could agents do to meet this condition?

\section{Equilibrium, authority, and understanding}

Rawls recommended striving for what he calls wide reflective equilibrium. To achieve wide equilibrium agents must compare their commitments and beliefs with alternative viewpoints. ${ }^{13}$ Elgin agrees: "An acceptable cognitive system must answer not just to my initially tenable commitments, but to ours" (Elgin 1996, p. 116, our emphasis). Of course, not every voice is worth hearing (certainly not on everything). There is "little to be gained by entertaining the economic views of someone convinced that extraterrestrial forces control the stock market" (cf. Elgin 1996, p. 117, 2017, p. 114). A rational move is to socialize one's epistemic endeavors, but not randomly. While we can learn from testifiers with many different kinds and degrees of competence, it will often be particularly effective to consult those who are more advanced regarding some relevant epistemic aim. In other words, a rational move is to turn to epistemic authorities. We have already given a structural characterization of epistemic authority. But how exactly can epistemic authorities help agents achieve reflective equilibrium, and on which competences and intellectual virtues do they rely when they do so?

Suppose you are in a state of what we called reflective imbalance (i.e., your system fails to be in equilibrium, and you are aware of this). Add that, although you are trying your best to achieve equilibrium, you are struggling. Maybe you have noticed a contradiction but find it hard to decide which content to preserve and which to discard. Suitable epistemic authorities can help you figure out how best to resolve the

13 "That is, ... we investigate principles people would acknowledge ... when they have had an opportunity to consider other plausible conceptions and to assess their supporting grounds" (Rawls 1974, p. 8). 
tension. Or imagine that you have observed a phenomenon $P$ under normal perceptual conditions, but the occurrence of $P$ doesn't fit your expectations. For example, suppose that in December you are walking along the Swiss bank of Lake Constance and observe what appears to be a flock of wild flamingos. However, you also have the wellgrounded, rational belief that there are no wild flamingos in Switzerland, or indeed anywhere else so far north in Europe. You call the local ornithological society and they confirm that a flock of wild flamingos has indeed recently settled at Lake Constance. They hypothesize that climate change has altered the conditions at Lake Constance in recent years and enabled flamingos to survive there. In general, an epistemic authority will be able to help you answer such questions as: Why am I observing P? Why does this phenomenon appear in the way it does? The authority might explain how to update-expand, contract, or rearrange-your system to integrate the information that $P$ is occurring. Moreover, if you had been expecting $P$ not to occur, the authority will be able to help you figure out which assumption or cluster of assumptions is responsible for your misguided expectations (e.g., "It is too cold for flamingos to survive at Lake Constance, and they don't have the right kind of food there"). Similarly, if your system is contaminated with bad or false explanations ("The flamingos must have escaped from a nearby zoo!"), the authority can show you what is wrong with these explanations, given currently acknowledged background information, epistemic standards, and available alternatives. ("The flamingos we are observing at Lake Constance have no tags, and there is no zoo nearby!") When laypeople interact with epistemic authorities in such ways, the latter serve as sources of learning, and the laypeople's cognitive progress amounts to progress in understanding. ${ }^{14}$

Note that the relevant procedures might also involve highly destructive steps. Consider cases in which you suffer from what we called an illusion of balance. You think that things fit together in your network, but are mistaken. An epistemic authority is in a position to make you aware that something went wrong in your self-assessment. She will show you the flaws in your views, e.g., by pointing to implausible consequences of your beliefs and commitments that you failed to notice, or by uncovering contradictions or other noetic dissonances. This is how Plato's Socrates often conducts philosophical discourse. Typically, an important first step is to shatter his interlocutors' hubris by demonstrating that their deep conviction that they know what they are talking about is false, or unwarranted, or in tension with other things they believe. Remember for example Euthyphro, who-initially very self-confidently-confronts Socrates with his strong conviction that he knows how to characterize the pious (hosion) and the impious (ahosion). Socrates rapidly corners Euthyphro and gets him to concede that he doesn't really know how to say what he means, and that his arguments, on whatever premises he tries to build them, constantly "turn round and walk away from us" (Plato, Euthyphro, 11b). Eventually Euthyphro gives up and walks away himself (following his arguments, so to speak, perhaps trying to catch and improve them), promising to face Socrates in continued conversation another time. ${ }^{15}$ In the Apology

\footnotetext{
14 Of course, such processes do not always require personal contact between agent and authority. We can also improve our noetic networks by reading articles and books, listening to the radio, watching documentaries, etc.

15 Similar capitulations can be found in many other of Plato's Socratic dialogues, see for example Charmides (162b); Crito (50a); Meno (79e).
} 
(23b), the general aim of the Socratic elenchus (his art of dialectic refutation, as we may translate) is said to be to explore whether anyone is wise (sophos) at all, and if any given person turns out not to be, to persuade them of this fact. Unfortunately every candidate Socrates meets, at least among politicians, poets, and craftsmen, turns out not to be wise. ${ }^{16}$

All this should not be misread as the claim that novices, or other interlocutors who understand less than an authority, cannot play important roles in furthering the latter's understanding. The layperson too can inspire the more experienced inquirer to think more deeply, to reconsider the presuppositions of a given claim, to consider things from different angles, or to support her views at points she had regarded as self-evident. ${ }^{17}$ All this will deepen her understanding. That said, it would nonetheless be misguided to maintain that less advanced interlocutors can assist epistemic agents in equally systematic, effective, or reliable ways as epistemic authorities can.

\section{Experts and authorities}

As noted earlier, Elgin herself discusses some social-epistemic dimensions of reflective equilibrium. "Rather than relying exclusively on considerations in my ken", she says, "I draw on the expertise of others, and they in turn draw on mine" (Elgin 1996, p. 114; cf. 2017, p. 112); we rely on the views of "competent peers with a suitable level of expertise" (2017, p. 115). Those with a suitable level of expertise are experts in a given discipline, so Elgin's suggestion is that we might attain adequate, socially integrated forms of reflective equilibrium by consulting disciplinary experts. However, though experts may serve as epistemic authorities, the latter have a skill-set that is broader than mere competence in their discipline. In fact, being an expert is not even necessary for being an authority.

First, there appear to be domains for which agents receive authoritative epistemic support from others, but for which there are no experts. For example, Williams (1995) and more recently Hills (2009) have influentially argued that there are no moral experts. ${ }^{18}$ Yet we consult others all the time when facing moral decisions, especially hard ones. Among those we consult are exemplars or role models whom we clearly treat, and refer to, as moral authorities. What we receive from them is moral understanding or minimally, justified moral belief, hence their moral authority involves epistemic authority. Like most philosophical arguments, the Williams-Hills argument is controversial. ${ }^{19}$ Since space prohibits entering this debate, our conclusion is thus tentative and conditional. There is a case to be made that justified moral beliefs and

\footnotetext{
16 For a helpful discussion of this aspect of the Socratic method, see for example Benson (2011).

17 For an illuminating argument that, e.g., religious authorities can (and should) learn from marginalized religious groups see Dormandy (2018b).

18 "[T] here are, notoriously, no ethical experts", Williams argues. "[T]he model of a theoretical expert does not apply to the ethical case" (Williams 1995, pp. 205, 206). See also Zagzebski (2012, p. 5), who argues that "the existence of expertise is typically denied in any domain pertaining to value or religion.".

19 A prominent criticism, for example, comes from Jones and Schroeter (2012), who also discuss and reject a number of different arguments to the effect that there are no moral experts.
} 
moral understanding can be obtained from morally advanced interlocutors even though there are no moral experts. If so, some authorities don't constitute experts.

A second argument is straightforward. Epistemic authority, as our above characterization made clear, is an essentially social notion. Croce (2018a) puts it this way: whether $\mathrm{S}^{*}$ is an epistemic authority for $\mathrm{S}$ is subject-dependent; it depends on who $\mathrm{S}$ is. Being an expert, however, is subject-independent. ${ }^{20}$ Consequently, someone's position as an authority may vary with respect to different persons while her position as an expert does not. Consider a child who seeks advice from her elementary school teacher on some elementary math question. The teacher is in a position to help and constitutes an epistemic authority for the child. But elementary school teachers are not typically expert mathematicians - they do not need to be. Being an expert, then, is not necessary for being an epistemic authority. Elgin might reply that on her view (as we saw), experts are "those who are competent, conscientious, and suitably sensitive to the level of confidence that their evidence supplies" (2017, p. 116), and that this will usually apply to math teachers. This may be correct, but since one would not classify the elementary school algebra teacher as a disciplinary expert in algebra, ${ }^{21}$ Elgin's idea requires fine-tuning.

Perhaps the most prominent account of expertise is Alvin Goldman's, on which experts must (1) "possess a substantial body of truths in the target domain" and (2) have "a capacity or disposition to deploy or exploit this fund of information to form beliefs in true answers to new questions that may be posed in the domain". Importantly for our purposes, Goldman emphasizes that "some non-comparative threshold of veritistic attainment must be reached" (2001, p. 145). On Goldman's view, if the teacher fails to meet this threshold or lacks this disposition, then she is not an expert. ${ }^{22}$ In more recent work Goldman suggests that:

$\mathrm{S}$ is an expert about domain D if and only if (A) $\mathrm{S}$ has more true beliefs (or high credences) in propositions concerning $\mathrm{D}$ than most people do, and fewer false beliefs; and (B) the absolute number of true beliefs $\mathrm{S}$ has about propositions in D is very substantial (Goldman 2018, p. 5).

This may also rule out the average elementary school teacher as an expert in algebra. Thus on this account too being an expert is not necessary for constituting or acting as an epistemic authority.

Nor is a high level of expertise - one that is high enough for being an expertsufficient for epistemic authority; even an objectively high level of expertise may not be enough to render $\mathrm{S}^{*}$ an authority for $\mathrm{S}$. As noted, epistemic authority is subjectdependent. So suppose that $S^{*}$ is an expert, but $S$ is approximately on a par with $S^{*}$. Then $\mathrm{S}^{*}$, though being an expert—and, as it may be, an epistemic authority for many others in the relevant epistemic community-is not an authority for S.

\footnotetext{
20 See also Constantin and Grundmann (2018), who argue along very similar lines.

21 She may of course be an expert about how to teach elementary algebra.

22 For a different veritistic account of expertise see Fricker (2006). Her account also excludes our teacher as an expert. Illuminating criticisms of both Goldman's and Fricker's veritistic approaches have been made by Watson, J.C (2018) and Watson, L (2018), who develops an alternative definition. Discussing Watson's approach is beyond the scope of this paper.
} 
Of course, none of this is to deny that there are-perhaps many-epistemic authorities who are also experts; the two classes overlap. We may call epistemic authorities who are also experts expert authorities. ${ }^{23}$ Our arguments just show that the two notions should be kept apart, and that it is the notion of epistemic authority, rather than expertise, that an account of the social dimensions of reflective equilibrium should invoke. ${ }^{24}$

The literature also contains a functional account of expertise the spirit of which is akin to our characterization of epistemic authority. For example, David Coady argues that an expert is "someone laypeople can go to in order to receive accurate answers to their questions" (2012, p. 39). Goldman (2018) also flirts with this approach (which is sometimes called the "service conception"), except that he is not concerned with understanding:

$\mathrm{S}$ is an expert in domain $\mathrm{D}$ if and only if $\mathrm{S}$ has the capacity to help others (especially laypersons) solve a variety of problems in D or execute an assortment of tasks in D which the latter would not be able to solve or execute on their own. $\mathrm{S}$ can provide such help by imparting to the layperson (or other client) his/her distinctive knowledge or skills (Goldman 2018, p. 4). ${ }^{25}$

Now Goldman also urges — we believe rightly - that it is important to know the ground or basis of the capacities in question. His answer invokes the "truth-linked" or "veritistic" conditions quoted above: experts must have more true beliefs and fewer false ones in their domain than most members of their epistemic community, and the absolute number of their true beliefs must be substantial. On this account, the elementaryschool teacher does not generally come out as an expert, which is the right result. However, the teacher clearly has the capacity to "help laypersons": he serves as an epistemic authority for his pupils. But what explains this ability? It is not the amount of his true mathematical beliefs, for that amount is not sufficiently substantial. We are left, then, with a crucial question: what other factors beyond or instead of possessing a substantial body of true disciplinary beliefs can account for an agent's ability to (systematically and reliably ${ }^{26}$ ) guide less experienced inquirers in their attempts to achieve reflective equilibrium or understanding?

\footnotetext{
23 Watson, J.C (2018) and Watson, L (2018) uses this term, though in a slightly different sense than we do.

24 For a detailed comparison of Goldman's earlier approach with his later, "novice-oriented" account of what it takes to be an expert, see Croce (2019). Drawing on convincing counterexamples, Croce eventually rejects the novice-oriented approach. Instead, he argues for what he calls a "research-oriented" account according to which " $\mathrm{S}$ is an expert in domain $\mathrm{D}$ if and only if... S has the capacity to contribute to the epistemic progress in D. S can provide such help by offering true answers to the questions under dispute in D" (2019, p. 3). Space prohibits discussing the dialectic of Croce's overall case, but we concur that, in order for someone to play the functional role that Goldman assigns to experts and that we assign to epistemic authorities, she must possess what Croce calls "novice-oriented abilities". In the next section, we examine what we take to be a central ability or virtue of this kind.

25 Christian Quast also offers a "practical explication" in this vein: "[S]omeone is an expert just in case... she is competent enough to relatively easily succeed in service-activities which are comparatively difficult for some contextually relevant reference group" (2018, p. 23).

26 These qualifications exclude cases in which an authority produces understanding in her interlocutors by happy accident. This can certainly happen, and when it does, the epistemic virtues we discuss in the next section, particularly epistemic empathy, are not required to generate understanding. Thanks to an anonymous referee who requested clarification of this point.
} 


\section{Epistemic empathy}

Recent debates on epistemic authority have largely focused on which epistemic skills and virtues agents must possess and activate in order to identify and rationally respond to epistemic authorities. ${ }^{27}$ But the foregoing discussion also puts a different question on the agenda: if certain authorities have the ability to guide interlocutors in their quest for understanding, then which skills and competences does this require?

We propose that certain intellectual virtues will play a role here, including traditional ones such as intellectual thoroughness, fair-mindedness, or perseverance. There is also another epistemic virtue however, which, though largely neglected in the literature, plays a crucial role in this context. We call it epistemic empathy. ${ }^{28}$ In a first approximation, epistemic empathy is the ability—or, if exercised, the mental state — of putting oneself in someone else's epistemic position and of inspecting certain areas of it, thereby learning how the world looks from that perspective. To avoid misunderstandings: Our claim is not that epistemic authorities can always fully achieve this. Typically, there will be limits, be it because the epistemic distance between the interlocutors is too great, be it for principled reasons concerning particular experiences or perspectives of the agent that are hard or impossible for her to share with those who lack such perspectives. So, depending on the interlocutors, attempts to empathize epistemically may succeed to a greater or lesser extent, and certain perspectives may even in principle be inaccessible to outsiders. All this does not undermine the claim, however, that epistemic empathy exists, and that attempts to engage in it will often constitute a desirable social-epistemic goal.

Characterizations of empathy vary widely. A major divide separates views that focus on affective phenomena and those that construe empathy more broadly in terms of emulating other peoples' cognitive (but not necessarily emotional) perspectives. For example, Karsten Stueber (2006, p. 28) argues that empathy is "a form of inner or mental imitation for the purpose of gaining knowledge of other minds". More recently Justin Steinberg (2014, p. 50) says, similarly, that "empathy involves taking up the perspective of another, which means understanding something about the content of another's mind." Our proposal is in line with such more general approaches that allow for non-affective forms of empathy. Moreover, our specific notion of epistemic empathy must be understood broadly. In an Elgin-style framework, for example, the relevant areas of a noetic network (and thus possible targets of epistemic empathy) include not only knowledge and belief, but also commitments, acceptances, various

\footnotetext{
27 A notable exception is Croce (2018a), who explicitly addresses the abilities that authorities must possess qua authorities. Critically discussing Zagzebski (2012) and Jäger (2016) proposal that "Socratic authorities" are sources of understanding, he argues that both what he calls "authorities of understanding" and "authorities of belief" must possess "virtues that allow an expert or authority to properly address a layperson's epistemic dependency on them" (p. 494). Though Croce does not use an Elgin-style, holistic epistemology as his springboard, and though his approach differs from ours in other important respects, we concur with his general idea that "someone is an [epistemic] authority for another insofar as she responds to (some of) his epistemic needs" (p. 479).

28 Croce (2018a, p. 494) argues that "in order for one to be an epistemic authority..., one is required to display novice-oriented abilities", and among the abilities he suggests is a virtue he calls "intellectual empathy" (ibid.). This seems to be in the spirit of our proposal, yet, Croce does not discuss this virtue, so it is hard to tell how he would wish to construe it.
} 
kinds of experience, methods of inquiry, cognitive goals and values, as well as relations among these items, such as relations of support, conflict, and so forth. Such items too are in the target set of (acts of) epistemic empathy. ${ }^{29}$

Importantly, the epistemic empathizer need not endorse the view that she empathizes with. Instead, she preserves cognitive and evaluative distance, remains aware of (and typically stands by) her own view, which she is in a position to compare with the view she empathizes with. For example, if an agent believes that $p$ whereas an authority believes that not- $p$, the latter's epistemic empathy does not involve her switching to the belief that $p \cdot{ }^{30}$ Instead, in such cases the empathizer identifies, but does not adopt, the agent's belief and sees how it is embedded in the agent's system. Along similar lines, we can understand what a false theory states despite the theory's being false. Here, too, we realize how things look from the perspective of the system, but do not endorse it. This does not rule out, of course, that the epistemic empathizer also shares attitudes with her interlocutor. For example, while disagreeing with him about whether $p$, she may nonetheless share his epistemic goals, the belief that q, or his acceptance of r. Moreover, like such objects of epistemic empathy, nor are the attitudes that constitute the authority's epistemic empathy restricted to beliefs. They too can be of various kinds. They may consist of (justified, or reliable, rational, apt...) beliefs, partial beliefs or credences, attitudes of mere acceptance, knowledge and, of course, understanding.

Empathy is standardly taken to be a success concept, and epistemic empathy is no exception. Compare affective empathy: If you feel bereft on your neighbor's behalf because her partner has left her, yet rather than being unhappy about this herself she is in very good spirits, you do not empathize with her. Your mental state has missed its target, which is her mental state. That said, empathy is not an all-or-nothing affair. An epistemic empathizer may correctly represent some aspects of her interlocutor's epistemic profile but misconstrue others. ${ }^{31}$

This picture can be refined. Epistemic empathy can be local or extended and shallow versus deep. It is local insofar as it concerns only certain regions of an epistemic system. The more subsystems the authority empathizes with, the farther her empathetic insight extends. Moreover, if the authority's empathy encompasses relatively few aspects of a given agent's noetic system or subsystem, her empathy is shallow; her empathy is deep to the extent that she correctly represents more aspects. This observation also sheds light on the fact that some epistemic authorities are better than others, and on the fact that some are better in some respects, whereas others are better in other respects. An important comparative dimension is how local or extended, and how shallow or deep, a given authority's epistemic empathy is. If you can choose between consulting someone who appears to have shallow and local epistemic empathy with you, thereby understanding you only in a shallow and local fashion, and someone who appears to

\footnotetext{
29 An even broader form of cognitive empathy is what may be called noetic empathy. It would include not only epistemic empathy, but also, for example, projecting oneself into another person's volitional and emotional profile.

30 Thanks to an anonymous referee for pressing us on this question.

31 In this respect, epistemic empathy does not differ from affective empathy. The latter too can be deep or superficial, depending on how well the empathizer represents the complexities of another person's emotional state (e.g., its intentional profile, phenomenal quality, or intensity).
} 
bear deep and extended epistemic empathy towards you, it might be wise to go for the latter.

Here are some illustrations of how epistemic empathy works. Take our flamingosin-December-at-Lake-Constance example (which is inspired by a true incident). You call the local ornithological society and inform them that you observed what appeared to you to be a flock of flamingos on the Swiss shore of Lake Constance. "However," you remark, "I am pretty sure that wild flamingos don't live on Lake Constance, so might they have escaped from a nearby zoo?" The expert replies that, yes, Lake Constance was previously not a flamingo habitat and that, indeed, wild flamingos have never before lived in Switzerland or this far north in Europe. "Yet," she explains, "this winter a flock of wild flamingos has settled at Lake Constance; we know that they did not escape from a zoo. Our experts believe that their presence can be explained by climate change. Nowadays the winters at the Lake are much milder than in the past." What the authority has done is extrapolate several features of the questioner's epistemic system from what the latter explicitly reveals, including his reasons for disbelieving that the flamingos at Lake Constance came from the wild. For example, the authority premises her response on the hypothesis that the interlocutor believes that wild flamingos still don't live that far north in Europe and that they are fit for areas with a much milder climate than today's Switzerland. Yet, the authority herself neither shares these reasons nor the belief or conjecture they support (namely that "the flamingos at Lake Constance have escaped from a nearby zoo"). She has superior knowledge and understanding to her interlocutor, and in light of what she gathers about his noetic system (including that he is aware of the basics of climate change, which she does not bother explaining to him), she provides him with information he needs to update it and to improve his understanding of the phenomenon at issue. In this case, the interlocutor's update may involve connecting two previously unrelated elements of his noetic network, namely the perceptual data and beliefs he has about the flamingos, on the one hand, and what he knows about climate change on the other.

Next consider some examples from fiction. A famous epistemic authority is Conan Doyle's Sherlock Holmes, who is regularly a few steps ahead of his friend Dr. Watson (let alone other characters). Sometimes Holmes and Watson share the same evidence, and yet Holmes interprets and explains it with more skill and explanatory creativity. Other times, Holmes uses better methods of inquiry or is more observant in collecting evidence in the first place. Holmes often explains to Watson which clues suggest which hypothesis, and in so doing he projects himself into Watson's less sophisticated thought patterns and guides him, by anticipating how Watson will reason, through noetic processes that eventually lead Watson to form the correct view about the case at hand. (Sometimes Watson remains clueless in spite of Holmes's prompting and Holmes just has to give him the answer. In such cases, Holmes fails to serve as a source of understanding.) Such examples are not confined to lighter fiction. Consider the intellectual interactions between the philosopher and Franciscan friar William of Baskerville and his intellectual and spiritual student, the Benedictine novice Adso of Melk, in Umberto Eco's The Name of the Rose. Step by step, the two discover what lies behind the mysteries and murders that haunt the Benedictine abbey they are visiting. (It turns out that the disturbing events are connected with the fact that the abbey's labyrinthine library contains the only surviving copy of the lost second book of Aristo- 
tle's Poetics.) Adso often comes up with various incomplete or erroneous hypotheses, yet even when he doesn't explicitly lay them out, William tends to know or anticipate them. What is going on is that William, who is a great intellectual authority for Adso and more generally for the relevant epistemic community (of $14^{\text {th }}$ century monks and theologians), enjoys great empathetic insight into Adso's overall noetic system. William guides Adso through processes of correcting and updating false assumptions, and leads him to see the relevance of certain data that he misinterpreted or overlooked and to draw the right conclusions. ${ }^{32}$

A fourth example comes from philosophy itself. The ways in which William relates to Adso have Socratic features. In Sect. 3 we mentioned Socrates, whom Plato portrays as someone who, though often claiming ignorance about whatever philosophical question arises, has the intellectual and dialectical skills to show his interlocutors where their reasoning goes astray. We said above that these include the skills to destroy the agents' (especially the sophist's) hubris and their conviction that they know what they are talking about. We may add here that Socrates' effectiveness in his elenchus-his art of refuting his respondents' poorly grounded claims and getting them to concede the incoherence of their views - often involves anticipating the cognitive dynamics in which they will engage. This in turn requires the ability to project himself into their minds. After pinning down some claim $p$ that his interlocutor endorses, Socrates often anticipates additional beliefs and further commitments on the latter's part, only to demonstrate in a next step, when the interlocutor articulates these views, that they are inconsistent with $p$. Although (and because) this process is to some extent destructive, Socrates' insights into his interlocutors' noetic system, and his ability to convey them to his interlocutors, enable the latter to make progress in understanding.

Socrates also exercises the intellectual skill of what Watson, J.C (2018) and Watson, L (2018) calls the skill of good questioning. However, whereas Watson considers this skill from the perspective of agents who wish to gather information and use it for themselves (an important topic), in a Socratic dialogue the epistemic authority uses it to foster understanding in others. And an important condition for this application of the skill of good questioning, it seems, is the ability to exercise epistemic empathy. Only if you can project yourself into another agent's thinking in the ways we have outlined-only if you can construct a sufficiently detailed picture of the interlocutor's noetic network, with both its good parts and its problematic areas-will you be able to ask questions that prompt her to improve that system and bring it into equilibrium.

In Sect. 4 we distinguished experts from authorities, but conceded that the two classes overlap. ${ }^{33}$ We can add now that an (expert) authority who is able to guide her interlocutors in their attempts to achieve or improve their understanding, will be epistemically empathetic. Note that we are not claiming that epistemic empathy is necessary for producing understanding in one way or another. We maintain instead

\footnotetext{
32 Interestingly, William appears less insightful and empathic regarding the emotional and erotic subtleties of Adso's love affair. We cannot go into details here. Suffice it to say that, on our view, there are no hints that Eco wishes to suggest that in general epistemic empathy is somehow antagonistic to affective empathy. And indeed, why would it be?

33 Note, however, that this does not suggest that the two notions should not be kept apart. We have argued that special disciplinary expertise is neither necessary nor sufficient for epistemic authority Thanks to an anonymous referee for pressing us about whether experts with empathy can constitute authorities.
} 
that epistemic empathy is necessary for having the ability (deliberately and reliably) to produce understanding in others. ${ }^{34}$ Surely an authority could produce understanding by happy accident and without epistemic empathy. Yet in such cases, this result would not be attributable to the authority's ability to guide or teach her interlocutor. (Abilities are standardly construed as dispositions or potentialities which, in the right circumstances, reliably produce certain results.)

The above examples illustrate this point. William of Baskerville may be an expert in philosophy, theology, church dogma, and so on. But he would not be a systematic, reliable source of understanding for Adso if he could not epistemically empathize with him. Similar observations apply to our Holmes and Socrates examples. Arguably, these agents too have special expertise. Yet without epistemic empathy, they could not teach and guide their interlocutors in improving their understanding. Consider the following analogy. Imagine a vast network of water reservoirs, akin, e.g., to a system of Nepalese rice terraces, most of which are connected through a complex channel network. Some of the reservoirs are filled, others contain some water but are not full, and other areas are entirely dry-either the higher-level reservoirs and the channels and ditches that would fill them are dry or closed off. Suppose that the system is so large and complex that the farmer who is in charge, though he tries hard to fill as many lakes and ponds as possible so as to keep as many areas as possible fertile, can only progress slowly and laboriously on his own. Many fields remain dry, many remain with little if any water, various channels are blocked, and watering other fields would require building new channels from scratch. One day, an experienced fellow-farmer visits the site and offers help. She brings maps of the whole area and realizes where things go wrong. Importantly, she has the competence to identify areas of minor or major significance and to judge which operations would be most effective. Some actions will have an "explosive" effect: when certain channels are opened, large and important areas of the whole territory become flooded or imbued simultaneously. We may add that, since the area is vast but time is short, during each visit the visitor can only inspect and improve limited parts of the territory. This picture illustrates the holistic way in which epistemic authorities operate when exercising epistemic empathy. The lakes, we may suppose, correspond to significant beliefs, important commitments, central acceptances, or pivotal epistemic goals of their interlocutors; ponds correspond to less significant subsystems, and the channels and ditches illustrate support relations. An authority may initially gain insight only into limited parts of an interlocutor's system, but is in a position to extrapolate where the most effective work can be done in order to pursue the cognitive goal of filling and connecting cognitively "dry" areas.

To summarize what we have argued so far: epistemic empathy is a social-epistemic virtue, because it helps improve people's epistemic situation (as opposed e.g. to their emotional situation). Moreover, it is a social epistemic virtue, because its primary or immediate target is other peoples' epistemic states and episodes. ${ }^{35}$

\footnotetext{
34 Thanks to an anonymous referee for requesting clarification of this point.

35 This is not to deny that epistemic empathy may also help the empathizer. A good teacher also learns from her pupils. Compare emotional empathy: this too offers opportunities for the agent to deepen her awareness of her own emotional states and dispositions. Yet, the primary orientation of empathy is outward, not inward; we empathize with others, not with ourselves (at least not with our current selves).
} 
Epistemic empathy is a social epistemic virtue because it constitutes an epistemic excellence. Corresponding to different traditions in virtue epistemology, this may be spelled out in different ways. According to virtue reliabilists such as Ernest Sosa or John Greco, epistemic virtues are cognitive faculties or abilities the exercise of which reliably promotes epistemic ends. Traditional examples are vision, memory, introspection, rational intuition, etc. Whereas such faculties have individualistic epistemic targets, however, epistemic empathy is essentially a social virtue, since it is concerned with other people's intellectual condition. As for responsibilist traditions in virtue epistemology, as influentially developed, e.g., by Linda Zagzebski, conceive of epistemic virtues not only as reliable faculties, but also as intellectual character traits that agents can deliberately influence. Whereas reliabilist virtues can operate sub-personally, character traits are so-called personal excellences. However, as Jaeson Baehr (VE) has argued, both kinds of virtues contribute to our overall intellectual wellbeing. If this is so, the contrast between the two traditions is less dramatic than meets the eye. What matters for present purposes is that epistemic empathy can also combine both sorts of virtue. It is a competence which, if operating under the right conditions, reliably furthers the corresponding epistemic goals (in some standard reliabilist sense); but it is also a personal excellence that agents can deliberately train and cultivate in their attempts to form their intellectual character.

\section{Conclusion: authorities as sources of understanding}

We have explored some social-epistemic dimensions of the conceptual connections between reflective equilibrium and objectual understanding. We started with Catherine Elgin's proposal that an agent's achieving or approaching reflective equilibrium in her noetic profile provides her with understanding and argued that epistemic authorities often help agents make this sort of progress and thus often serve as sources of understanding. This thesis departs from mainstream accounts of epistemic authority, on which epistemic authorities transmit (individual) beliefs and knowledge to their interlocutors. After discussing various ways in which authorities help interlocutors to achieve reflective equilibrium, thereby acting as testimonial sources of understanding, we have looked more closely at the competences involved in such processes. An important yet hitherto underexplored virtue in this context is epistemic empathy. We have considered some core features of this notion, distinguished various of it's forms and aspects, and illustrated it with examples.

Yet, it may be asked, exactly how should we understand talk about serving as a testimonial "source" of understanding? Is the kind of noetic guidance epistemic authorities provide akin to the ways in which knowledge and belief can be transmitted via testimony $?^{36,37}$

\footnotetext{
36 Thanks to an anonymous referee for this question.

37 For helpful recent discussions of knowledge transmission and the debates on this topic from recent decades see the booklength study by Wright (2019), and Greco (2016). Greco distinguishes norms governing the acquisition of knowledge or information in an epistemic community from norms governing the distribution of knowledge in the community. The latter govern a special kind of epistemic transmission.
} 
We have expressed sympathy for non-reductionism about understanding (the view that understanding does not reduce to true beliefs or knowledge) and have followed Elgin and others in construing the epistemic items involved in understanding as not only beliefs, but also acceptances, epistemic commitments, epistemic goals, standards of inquiry, and so forth. In this framework, there are generally two ways in which we might construe an authority's help to the layperson in achieving reflective equilibrium, and corresponding to these are two ways in which an authority can serve as a source of understanding. The items she feeds into her interlocutor's network may or may not correspond to her own respective attitude. Suppose they don't. Then, even though the authority will help the interlocutor improve the equilibrium of his network, we should not characterize the situation as one of transmitting understanding. As Greco (2016, p. 483) remarks concerning knowledge transmission, "one cannot transmit what one does not have". Note that situations of this type may include cases in which, although the authority does not endorse what she offers the agent, the latter's network will be objectively improved. An example inspired by Elgin: Suppose that a young child tells you that humans evolved from hairy creatures who otherwise look a bit like humans but can climb and play games in trees. In an animal atlas, the child then shows you pictures of chimpanzees, gorillas, and orang-utans. "You mean that humans evolved from great apes?" "Yes, great apes!", the child replies. "Very well, something like that!", you respond and leave it at that. The conversation has arguably improved the child's understanding of the topic since it has learned a general name for what is an important categorization in this context. But you neither believe nor accept nor are implicitly committed to the claim that humans evolved from great apes. ${ }^{38}$

In other cases, by contrast, the epistemic authority does provide the interlocutor, via testimony, with parts of the authority's system, and in such cases talk of "transmitting understanding" seems appropriate. For example, consider a professor of evolutionary theory who explains to her 14-year-old child in some detail (and with epistemic empathy) how homo sapiens and anthropoid apes such as gibbons, gorillas, orang-utans, bonobos, and chimpanzees evolved from a common ancestor. Anticipating, in acts of epistemic empathy, where her interlocutor might feel puzzled, ask for evidence, and so forth, she distinguishes the claims that merit fairly firm beliefs from those meriting weaker forms of credence, different again from those which, given the current state of scientific inquiry, deserve no more than acceptance. The biology professor enjoys (a high degree of) understanding of the topic, and by handing over central parts of it, transmits understanding to her child. All this is not to say, of course, that when such "understanding transmission" takes place, then no epistemic work will be left to the

\footnotetext{
38 Malfatti (2019) explores a related, yet different case. Imagine a teacher who understands, but denies the truth of, the theory of anthropogenic climate change (which we will assume here is correct). Such a teacher fails to understand the phenomena of climate change-basically, because she entertains the wrong epistemic attitude (namely disbelief) towards the correct theory and what it describes. But suppose that in her lessons the teacher nevertheless presents the theory of anthropogenic climate change as true, and based on her assertions her students form the corresponding beliefs. As a result, they come to understand-not only the theory of anthropogenic climate change, but also the phenomena the theory describes and explains. In such a case, while the teacher arguably transmits understanding of the theory to her students, their understanding of the phenomena under consideration is instead being generated in the testimonial interaction. See Lackey (2008) for a famous, analogous argument in support of the claim that testimony can work as a generative source, not of understanding, but of knowledge.
} 
agent. However, our arguments show that a considerable amount of epistemic responsibility for whether or not, or to what extent, agents achieve understanding should be attributed to the epistemic authorities they consult.

Both the distinction between knowledge and understanding and the idea that pursuing epistemic goals is an essentially social enterprise have a long and venerable tradition. Indeed, they appear to be as old as philosophy itself. "Knowledge of many things teacheth not understanding", Heraclitus declared. ${ }^{39} \mathrm{He}$ also argued that the logos is common and took issue with those who live "as if they had a wisdom of their own" ${ }^{40}$ It looks as if Heraclitus was right. ${ }^{41}$

Acknowledgements Open access funding provided by University of Innsbruck and Medical University of Innsbruck.

Open Access This article is licensed under a Creative Commons Attribution 4.0 International License, which permits use, sharing, adaptation, distribution and reproduction in any medium or format, as long as you give appropriate credit to the original author(s) and the source, provide a link to the Creative Commons licence, and indicate if changes were made. The images or other third party material in this article are included in the article's Creative Commons licence, unless indicated otherwise in a credit line to the material. If material is not included in the article's Creative Commons licence and your intended use is not permitted by statutory regulation or exceeds the permitted use, you will need to obtain permission directly from the copyright holder. To view a copy of this licence, visit http://creativecommons.org/licenses/by/4.0/.

\section{References}

Anderson, C. (2014). Epistemic authority and conscientious belief. European Journal for Philosophy of Religion, 6, 91-99.

Baehr, J. (VE). Virtue epistemology. The Internet Encyclopedia of Philosophy. https://www.iep.utm.edu/ Baumberger, C., \& Brun, G. (2016). Dimensions of Objectual Understanding. In S. Grimm, C. Baumberger, \& S. Ammon (Eds.), Explaining understanding: New perspectives from epistemology and philosophy of science (pp. 165-189). New York: Routledge.

Benson, H. H. (2011). Socratic method. In D. R. Morrison (Ed.), The Cambridge companion to socrates (pp. 179-200). Cambridge: Cambride University Press.

Benton, M. A. (2014). Believing on authority. European Journal for Philosophy of Religion, 6(2014), $133-144$.

Boyd, K. (2017). Testifying understanding. Episteme, 14, 103-127.

Brun, G. (2014). Reflective Equilibrium without intuitions? Ethical Theory and Moral Practice, 17, 237-252.

Cath, Y. (2016). Reflective Equilibrium. In H. Cappelen, T. Gendler, \& J. Hawthorne (Eds.), The Oxford Handbook of philosophical methodology (pp. 213-230). Oxford: Oxford University Press.

Coady, D. (2012). What to believe now. Applying epistemology to contemporary issues. Malden, MA: Wiley. Cohen, J. (1992). An essay on belief and acceptance. Oxford: Clarendon.

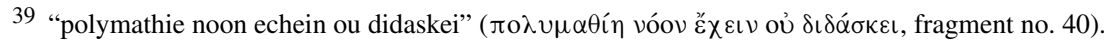

40 Fragment no. 2; the Greek has phronesis for what we translated with "wisdom".

41 Earlier versions of, or portions of this essay, were presented (by one or both of us) at the conference "Political Epistemology", organised by Klemens Kappel 2017 in Copenhagen; at the symposium "True Enough?", organised by Federica I. Malfatti and Christoph Jäger 2018 in Innsbruck; at the workshop "Epistemische Autorität, Autonomie und Vertrauenswürdigkeit", organised by Pedro Schmechtig 2018 in Dresden; and (via Zoom) at an international epistemology workshop, organised by Peter Brössel, AnnaMaria Eder, and Branden Fitelson 2020 in Bochum. We are grateful to the audiences and two anonymous referees of Synthese for their helpful comments and discussions. Special thanks for valuable suggestions go to Catherine Elgin and Katherine Dormandy.
} 
Constantin, J., \& Grundmann, T. (2018). Epistemic authority: Preemption through source sensitive defeat. Synthese. https://doi.org/10.1007/s11229-018-01923-x.

Croce, M. (2018a). Expert-oriented abilities vs. novice-oriented abilities: An alternative account of epistemic authority. Episteme, 15, 476-498.

Croce, M. (2018b). Epistemic paternalism and the service conception of epistemic authority. Metaphilosophy, 49, 305-327.

Croce, M. (2019). On what it takes to be an expert. The Philosophical Quarterly, 69, 1-21. https://doi.org/ $10.1093 / \mathrm{pq} / \mathrm{pqy} 044$.

Daniels, N. (2016). Reflective equilibrium. In E. N. Zalta (ed.), The Stanford encyclopedia of philosophy (Fall 2018 edn). https://plato.stanford.edu/archives/fall2018/entries/reflective-equilibrium/.

De Maagt, S. (2017). Reflective equilibrium and moral objectivity. Inquiry, 60, 443-465.

DePaul, M. R. (2005). Reflective equilibrium. In: Encyclopedia of Philosophy, 2nd edition (vol. 3).

Dormandy, K. (2018a). Epistemic authority: Preemption or proper basing? Erkenntnis, 83, 773-791.

Dormandy, K. (2018b). Disagreement from the Religious Margins. Res Philosophica, 95(2018), 371-395.

Ebertz, R. P. (1993). Is reflective equilibrium a coherentist model? Canadian Journal of Philosophy, 23(2), 193-214.

Elgin, C. Z. (1996). Considered judgment. Princeton: Princeton University Press.

Elgin, C. Z. (2017). True enough. Cambridge: MIT Press.

Ellis, W., \& McBrayer, J. P. (2019). a phenomenal defense of reflective equilibrium. Journal of Philosophical Research, 44, 1-12.

Fricker, E. (2006). Testimony and epistemic autonomy. In J. Lackey \& E. Sosa (Eds.), The epistemology of testimony (pp. 225-250). Oxford: Oxford University Press.

Fricker, M. (2007). Epistemic injustice: Power and the ethics of knowing. Oxford: Oxford University Press.

Friedman, R. B. (1990). On the concept of authority in political philosophy. In J. Raz (Ed.), Authority. New York: New York University Press.

Goldberg, S. (manuscript). The Speaker's expectation of trust. Book chapter, manuscript 2018.

Goldman, A. (ed.) (2001). Experts: Which ones should you trust? In Pathways to knowledge. Oxford: Oxford University Press (pp. 139-163).

Goldman, A. (2018). Expertise. Topoi, 37, 3-10.

Goodman, N. (ed.) (1953). The new riddle of induction. In Fact, fiction, and forecast. Harvard: Harvard University Press.

Greco, J. (2016). What is transmission*? Episteme, 13, 481-498.

Grimm, S. (2020). Transmitting understanding and know-how. In S. Hetherington \& N. D. Smith (Eds.), What the ancients offer to contemporary epistemology. New York: Routledge.

Hills, A. (2009). Moral testimony and moral epistemology. Ethics, 120, 94-127.

Hinchman, E. (2005). Telling as inviting to trust. Philosophy and Phenomenological Research, 70, $562-587$.

Hinchman, E. (2014). Assurance and warrant. Philosophers' Imprint, 14, 1-58.

Jäger, C. (2016). Epistemic authority, preemptive reasons, and understanding. Episteme, 13, 167-185.

Jones, K., \& Schroeter, F. (2012). Moral expertise. Analyse and Kritik, 2, 217-230.

Kelly, T., \& McGrath, S. (2010). Is reflective equilibrium enough? Philosophical Perspectives, 24, 325-359.

Kelp, C. (2017). Towards a knowledge-based account of understanding. In S. Grimm, C. Baumberger, \& S. Ammon (Eds.), Explaining understanding (pp. 251-271). New York: Routledge.

Keren, A. (2007). Epistemic authority, testimony and the transmission of knowledge. Episteme, 4(3), $368-381$.

Keren, A. (2014). Trust and belief: a preemptive reasons account. Synthese, 191(12), 2593-2615.

Lackey, J. (2008). Learning from words. Testimony as a source of knowledge. Oxford: Oxford University Press.

Malfatti, F. I. (2019). Can testimony generate understanding? Social Epistemology. https://doi.org/10.108 0/02691728.2019.1628319.

McMahan, J. (2000). Moral intuition. In H. LaFollete (Ed.), The Blackwell guide to ethical theory (pp. 92-110). Chichester: Blackwell.

McMyler, B. (2011). Testimony, trust, and authority. Oxford: Oxford University Press.

McMyler, B. (2014). Epistemic authority, preemption, and normative power. European Journal for Philosophy of Religion, 6, 101-119.

Moran, R. (2005). Getting told and being believed. Philosophers' Imprint, 5, 1-29.

Pritchard, D. (2010). Understanding. In D. Pritchard, A. Millar, \& A. Haddock (Eds.), The nature and value of knowledge. Oxford: Oxford University Press. 
Pust, J. (2000). Intuitions as evidence. New York: Routledge.

Quast, C. (2018). Expertise: A practical explication. Topoi, 37, 11-27.

Rawls, J. (1971). A theory of justice. 2nd Edition 1999, Cambridge, MA: Harvard University Press.

Rawls, J. (1974). The independence of Moral theory. In Proceedings and addresses of the American Philosophical Association 47, 5-22. Reprinted in S. Freeman (Ed.), John Rawls, Collected papers, Cambridge MA: Harvard University, 1999, 286-302.

Raz, J. (1986). The morality of freedom. Oxford: Oxford University Press.

Raz, J. (2009). The problem of authority: Revisiting the service conception. Between authority and interpretation (pp. 126-165). Oxford: Oxford University Press.

Ross, L. D. (2018). Is understanding reducible? Inquiry. https://doi.org/10.1080/0020174X.2018.156237.

Sliwa, P. (2015). Understanding and knowing. Proceedings of the Aristotelian Society, CXV, Part 1, 115, 57-74.

Steinberg, J. (2014). An epistemic case for empathy. Pacific Philosophical Quarterly, 95, 47-71.

Stewart, C. (2019). Expertise and authority. Episteme. https://doi.org/10.1017/epi.2018.43.

Stueber, K. (2006). Rediscovering empathy: Agency, folk psychology, and the human sciences. Cambridge, MA: MIT Press.

Ullmann-Margalit, E. (2007). Trust in authority. In G. Origgi (Ed.), The concept of authority (pp. 53-73). Rome: Fondazione Adriano Olivetti.

Walden, K. (2013). In defence of reflective equilibrium. Philosophical Studies, 166, 243-256.

Watson, J. C. (2018). The shoulders of giants: a case for non-Veritism about expert authority. Topoi, 37, 39-53.

Watson, L. (2018). Educating for good questioning: A tool for intellectual virtues education. Acta Analytica, 2018, 353-370. https://doi.org/10.1007/s12136-018-0350.

Williams, B. (1995). Who needs ethical knowledge?, Reprint. In id., Making sense of humanity and other philosophical papers (pp. 203-212), Cambridge University Press.

Wright, S. (2016). Epistemic authority, epistemic preemption, and the intellectual virtues. Episteme, 13, 555-570.

Wright, St. (2019). Knowledge transmission. Oxford: Oxford University Press.

Zagzebski, L. (2008). On epistemology. Belmont, CA: Wadsworth.

Zagzebski, L. (2012). Epistemic authority: A theory of trust, authority, and autonomy in belief. Oxford: Oxford University Press.

Zagzebski, L. (2014). Epistemic authority and its critics. European Journal for Philosophy of Religion, 6 , 169-187.

Zagzebski, L. (2016). Reply to Christoph Jäger and Elizabeth Fricker. Episteme, 13, 187-194.

Publisher's Note Springer Nature remains neutral with regard to jurisdictional claims in published maps and institutional affiliations. 